\title{
EL RENTISMO EMPRESARIAL EN MÉXICO
}

Mario Humberto Hernández López*

L os problemas del desarrollo escapan a la teoría ortodoxa -para la cual es un resultado inherente al crecimiento- que se centra en el uso óptimo de los factores de producción y las ventajas comparativas. Aunque esta teoría ha dejado de ser predominante en la academia, aún tiene portavoces en las esferas donde se define la política económica. Después de los magros resultados del neoliberalismo en América Latina y de sus graves efectos en las economías desarrolladas, evidentes luego de la crisis financiera, se ha vuelto la mirada a otras perspectivas y teorías, como los enfoques tecnologistas, para los cuales es posible lograr el crecimiento, y el desarrollo, mediante políticas que induzcan la innovación. Siguiendo el ejemplo de la industrialización de países tardíos tipo A (Corea del Sur, Hong Kong, China, Singapur, Malasia y Taiwán), se considera que con el trasplante de sus experiencias basadas en el fomento de la tecnología los países tipo в (América Latina) podrán escapar a la "trampa del atraso" (Rivera, 2009) y desencadenar el comportamiento innovador.

Sin embargo, la teoría institucionalista subraya la pertinencia de considerar los condicionantes institucionales de las políticas, de las

\footnotetext{
* Doctor en Economía, Investigador de la Facultad de Contaduría y Administración, Universidad Nacional Autónoma de México, Ciudad de México, México, [mario.humberto.hernandez@gmail.com]. Este artículo es un producto del proyecto de investigación "Matriz institucional, gobernanza corporativa e innovación: cinco países tardíos en perspectiva comparada", auspiciado por la UnAm. Agradezco los comentarios de los miembros del seminario "Instituciones, desempeño empresarial y desarrollo", de la Facultad de Contaduría y Administración de la UNAM. Una versión preliminar se presentó en el xx Congreso Internacional de Contaduría, Administración e Informática de la unAm-FCA, el 9 de octubre de 2015. Fecha de recepción: 16-10-2015, fecha de modificación: 22-04-2016, fecha de aceptación: 20-10-2016. Sugerencia de citación: Hernández L., M. H. "E1 rentismo empresarial en México", Revista de Economía Institucional 18, 35, 2016, pp. 257-275. DOI: http://dx.doi.org/10.18601/01245996.v18n35.13.
} 
estrategias empresariales y, en general, del comportamiento de los agentes. En particular, el institucionalismo histórico, representado por North (1993 y 2005), North et al. (2009) y Acemoglu et al. (2001) y otros autores, se distancia del institucionalismo de orientación más microeconómica cercano a la corriente principal (Coase y Williamson), y considera la influencia del poder en el diseño de políticas, lo que implica reconocer el conflicto y las asimetrías en la sociedad ${ }^{1}$. Una diferencia nada menor entre el enfoque de Coase y Williamson y el de North y otros, es que estos van más allá del enfoque contractualista centrado en los derechos de propiedad y los costos de transacción, que por lo demás es útil para esclarecer problemas de agente-principal. North (1993) retomó el análisis de la historia y del poder, y fue más allá del estudio de la información con base en la cual los agentes toman decisiones en un marco abstracto, piedra angular del institucionalismo de Coase y Williamson.

Este trabajo sigue el institucionalismo histórico porque ayuda a identificar la trayectoria de la propensión al rentismo. Es parte de una investigación sobre las condiciones institucionales en que se desempeñan los grupos empresariales en países tardíos y que condicionan su comportamiento. La unidad de análisis es lo que Mills (1957) 1lamó élite económica, una parte de la élite del poder. Guardando las distancias, busca identificar el comportamiento rentista en el desarrollo histórico-institucional para evaluar el curso económico de México en una perspectiva amplia, pero panorámica y no exhaustiva. Sostiene que el comportamiento rentista es producto de una relación perversa entre poder político y poder económico, que no induce a buscar la rentabilidad en la innovación, es decir, de la falta de incentivos para la acción productiva e innovadora.

Si bien el país ha tenido al menos dos grandes oportunidades para revolucionar el orden institucional: la Independencia y la Revolución, las coaliciones que se formaron después de esos cismas retomaron las conductas no innovadoras y preservaron el rentismo. Para fundamentar lo anterior se analiza el asentamiento del poder político y la formación de élites económicas en momentos clave como la Colonia, el México independiente, la posrevolución y el neoliberalismo. Y se describe cómo se formó la trayectoria histórica continua generada por el marco institucional que orienta la acción social. Puesto que se examinan los condicionantes institucionales, se dejan de lado aspectos exógenos como los vínculos con el mercado mundial y la economía

\footnotetext{
${ }^{1}$ El nuevo institucionalismo económico no es un cuerpo homogéneo de ideas, postulados ni agendas de investigación.
} 
estadounidense, que completan el cuadro, pero que se suelen sobredimensionar y oscurecen los condicionantes endógenos.

\section{EL DESEMPEÑO ECONÓMICO}

La trayectoria histórica es la tendencia de largo plazo del desempeño de un país en su camino al desarrollo, o su estancamiento en el atraso relativo. Ese desempeño no se puede explicar al margen de la historia, sino que está ligado directamente a ella dependiendo de cómo se estructura la sociedad, y sus momentos fundacionales son referentes clave para identificar la trayectoria que se forma a partir de comportamientos reproducidos históricamente (Rivera, 2014; Jeannot, 2010). Para examinar su origen es necesario reconocer que estos dependen de las instituciones que habilitan o restringen la acción al generar la estructura de incentivos. Por ello es fundamental la idea de North (1993) de que hay instituciones formales (normas, reglas, leyes) e informales (creencias, hábitos de pensamiento, códigos tácitos, pautas arraigadas de conducta), y de que estas últimas ayudan a explicar el cambio o la continuidad a lo largo de la historia, al estar incrustadas en la cultura. Los rasgos incorporados en la cultura tienden a prevalecer, pues se reproducen en forma continua por medio de las construcciones mentales a través del aprendizaje colectivo (North, 2005), si no hay impactos que alteren los hábitos arraigados.

La experiencia y el conocimiento acumulado crean patrones de conducta que orientan la acción de los agentes y se arraigan en la estructura social (Hernández, 2013b, 145), la cual moldea el futuro en un proceso que se auto-reproduce (histéresis institucional). E1 afianzamiento en la cultura lleva a que, así se reconozca que cierto comportamiento no es el mejor, los incentivos para actuar de manera distinta son escasos, poco efectivos, difíciles de coordinar y a la larga fallidos (Hoff y Stiglitz, 2002). Es decir, la dependencia de la trayectoria lleva a que los cambios sociales sean incrementales y no radicales, pues los agentes adaptan su acción para mejorar su posición dentro de lo que conciben como la realidad (North, 2005).

A esto se debe sumar el ejercicio del poder, el factor que preserva la trayectoria y en general se beneficia de ella reforzando la estructura institucional (Arellano y Lepore, 2009), la cual condiciona el comportamiento de los agentes e impone restricciones al desempeño económico y social, sometiéndolos al entrecruce de un conjunto de incentivos diseñados ex profeso a partir de hábitos mentales inconscientes; ese entrecruce define el sentido común y las creencias que 
guían la acción hacia el orden o el conflicto, conformando una matriz institucional (North, 2005).

La coalición de grupos con poder, la élite del poder de Mills, establece los derechos de propiedad y el sistema mediante el cual se impone el orden social y se dirime el conflicto. Además, delimita los medios, es decir, los factores tangibles (máquinas, instrumentos, herramientas) e intangibles (conocimientos, habilidades, creencias) de producción que propician la eficiencia, incluida la tecnología (ibíd.). La matriz institucional y los medios condicionan el comportamiento de los capitalistas, que son propensos a innovar cuando la búsqueda de soluciones recurre a la ciencia y la tecnología como fuente de nuevas combinaciones para resolver las contingencias. De modo que

el medio [...] impone determinada lógica de acción a los empresarios [...], si el medio es productivo, existirá un incentivo natural a favor de una masa crítica de empresarios innovadores, en caso contrario no lo habrá [...] las prácticas gerenciales se transmiten en buena medida por legados inconscientes que revalidan la gravitación de lo colectivo sobre las mentalidades (Jeannot, 2002, 46).

\section{INNOVACIÓN VERSUS RENTISMO}

Lo que se ha dicho hasta aquí indica que los agentes, empresarios y trabajadores no actúan en un marco abstracto de racionalidad maximizadora, sino a partir de experiencias previas, conocimiento tácito e información asimétrica, así como de creencias y valores explícitos e implícitos con los cuales intervienen en el mercado y otras esferas sociales, adaptándose al entorno para lograr sus objetivos.

Las instituciones y las formas de organización son entonces esenciales en la dinámica y la acción regular de las empresas, sus propietarios y sus directivos cuando enfrentan el proceso de innovación (Jeannot, 2002). De acuerdo con Schumpeter, el sistema capitalista es endógenamente dinámico, y lo relevante no es cómo alcanza el supuesto equilibrio sino cómo se perturba y se transforma a sí mismo en una espiral de crecimiento económico y cambio social. Su célebre "destrucción creadora" transforma la estructura económica desde dentro, por obra del empresario innovador que actúa como agente dinámico cuando busca nuevas combinaciones productivas en un contexto de incertidumbre (Schumpeter, 1997, 78; 1983, 120); no basta ser propietario para ser un empresario innovador. A diferencia de este último, el capitalista común o administrador, una vez que la empresa pasa a ser una sociedad por acciones y da cabida a los accionistas, se dedica a la rutina de aumentar los beneficios mediante los procedimientos habituales: 
Y ello es así porque todo hábito y conocimiento, una vez adquirido, se enraíza tan profundamente en nosotros, como un terraplén ferroviario en la tierra. No requiere ser renovado continuamente, ni reproducido en forma consciente, sino que se hunde en el estrato de lo subconsciente. Se transmite normalmente por herencia, aprendizaje, educación, presión del medio, casi sin fricción (ibíd., 94).

Cuando ese comportamiento se vuelve habitual, y seguir la rutina es la tarea de la tecnoestructura (Galbraith, 1984), el empresario innovador, que pertenece a un "tipo especial", pasa a desempeñar el papel de "conducir los medios de producción a nuevos caminos" (Schumpeter, 1997, 97 y 98) y a experimentar un "gozo creador" en el ejercicio de su energía e ingenio (ibíd., 102). No todos los capitalistas o empresarios son de por sí innovadores, y los que apuestan por nuevas combinaciones "son mucho menos numerosos que aquellos que disponen de la posibilidad 'objetiva' de hacerlo" (ibíd., 91). Existen entonces diferencias en el desempeño de los hombres de empresa: el empresario, el capitalista y el director de empresa (ibíd., 80, 85 y 93). La diferencia no es formal, relacionada con la propiedad jurídica o el cargo, es más bien el tipo de comportamiento. El primero es innovador, el segundo proporciona capital o crédito, y el directivo sigue las pautas rutinarias de la gestión administrativa. La diferencia entre quienes innovan y quienes realizan rutinas carentes de creatividad y mantienen los niveles de productividad ubica a estos últimos en la categoría de los rentistas.

Desde este punto de vista el rentismo es la obtención de beneficios sin aumentos de la productividad, como cuando aumenta el precio de los bienes porque la oferta está monopolizada o porque no hay sustitutos perfectos, como en el caso del petróleo. También son rentistas los accionistas que reciben dividendos sin participar directamente en la operación de la unidad productiva, o los financistas que devengan intereses por inversiones de capital ficticio, lo que hoy se llama financiarización (Serfati, 2013).

Este concepto se remonta a los economistas clásicos -Smith, Ricardo y Malthus- que analizaron la renta de la tierra en un contexto en que era necesario aumentar la oferta de alimentos, donde las tierras más productivas eran cada vez más rentables a medida que se cultivaban tierras menos fértiles, de modo que los precios agrícolas aumentaban con el incremento de los costos de producción, en beneficio de los propietarios de la tierra más fértil, que obtenían una renta extraordinaria por el monopolio de ese recurso natural. Para Marx, el rentismo también estaba asociado a la renta de monopolio, es decir, al sobreprecio impuesto por quienes concentran la oferta como resultado de la concentración y centralización del capital. 
Veblen (1974) también se refirió a este tema cuando diferenció las clases que componen la sociedad capitalista moderna y las actividades de tipo pecuniario e industrial. La clase ociosa, la que está exenta de tareas manuales y tiene mayor prestigio social, realiza actividades pecuniarias como las finanzas, el comercio y la administración, es decir, aquellas que generan rentas sin participar directamente en la producción. Las clases trabajadoras se ocupan de las actividades industriales. Cada actividad exige rasgos o inclinaciones diferentes; las de tipo pecuniario, un espíritu depredador, y las industriales, laboriosidad y disciplina. Las actividades pecuniarias buscan la rentabilidad por sí misma, no por la productividad.

Según los autores mencionados, el rentismo es ajeno a la eficiencia productiva, y los grupos improductivos que extraen rentas, lejos de contribuir a la modernización económica, son agentes de retraso. "La renta puede definirse como un derecho de propiedad que da a su poseedor el poder (incluso coercitivo) para acaparar de manera regular una parte del valor creado o de las riquezas existentes"(Serfati, 2013, 6). El rentismo es retardatario porque toda la sociedad termina pagando, en forma directa o indirecta, un tributo a los propietarios de la tierra, de recursos naturales o de instalaciones y tecnologías altamente concentradas o protegidas por derechos de propiedad (patentes) que favorecen la actividad productiva o cuya producción tiene una oferta inelástica.

La perspectiva schumpeteriana hoy es muy aceptada y difundida. Y el hecho de que no en todas partes exista un empresariado innovador suscita algunas preguntas: ¿el capitalismo es del mismo tipo en todos los países?, ¿es neutral a las condiciones institucionales e históricas de cada nación? La concentración de las innovaciones, sobre todo las de índole tecnológica, en los países desarrollados y en los del sudeste asiático indica que el capitalismo tiene gran variedad institucional, la cual se refleja en su clase empresarial.

El desarrollo de la organización capitalista, apoyado en el cambio técnico y en la ampliación de la masa de capital para sufragar las nuevas inversiones, ha pasado por varias etapas, de la pequeña unidad productiva de propiedad individual administrada por su propietario hasta la gran sociedad por acciones cuyos propietarios no intervienen en la gestión, y la dejan en manos de los directivos y la tecnoestructura, donde la propiedad y el control están separados y el simple aporte de capital da derecho a participar en los beneficios, de modo que los propietarios o accionistas son rentistas, así como el empresario que ejerce el control pero solo realiza actividades rutinarias y carece de espíritu creativo e innovador. 


\section{LA IMPRONTA DEL RENTISMO EN MÉXICO}

En la historia hay momentos propicios para alterar la trayectoria de atraso que prevalece en los países en desarrollo. En México todavía subsisten grandes desigualdades entre la élite y el conjunto de la población, "los comunes" de North et al. (2009). A lo largo de su historia algunos condicionantes han actuado como "camisa de fuerza" que constriñe la capacidad social y conformado una estructura que soslaya la innovación. El resultado ha sido una trayectoria en la que el retraso se impone a los intentos desarrollistas esporádicos y desarticulados.

La revisión de esta historia puede dar claves para entender el presente explorando la formación de las élites que sustituyeron a las que regían durante el régimen colonial (Acemoglu et al., 2001). La continuidad institucional permite entender la persistencia de un comportamiento arraigado como el rentismo.

\section{LA COLONia}

En la etapa colonial, la Nueva España era administrada por la Corona ibérica mediante un sistema autoritario y centralizado que expoliaba la riqueza, imponía trabas al comercio con otros países y extraía oro y plata en forma de ingresos fiscales para la metrópoli. Las restricciones al comercio y la pesada carga impositiva limitaron la productividad y la generación interna de riqueza. Coatsworth identificó dos obstáculos para el desarrollo económico en ese periodo: transportes inadecuados y una deficiente organización económica $(1990,94)$. Esas trabas limitaron el desempeño económico de México en comparación con el de Estados Unidos a comienzos del siglo xIX, pues la carencia de un sistema fluvial obligaba a transportar los productos por tierra a un costo elevado. Esa dificultad se empezó a superar con la construcción de vías férreas durante el porfiriato. Coatsworth también señaló que la metrópoli, mediante el gobierno virreinal, el Consejo de Indias y otras autoridades, impuso trabas burocráticas ventajosas para la Corona y adversas a la actividad productiva:

un medio institucional seriamente deficiente para la actividad empresarial. La
organización de la actividad económica estuvo inmersa en un conjunto de
medidas políticas, leyes e instituciones que ampliaron, en lugar de reducir, la
brecha entre los beneficios privados y los sociales de la actividad económica
[... La ley o la práctica existentes iban en contra de una empresa más pro-
ductiva, o de leyes y prácticas nuevas, necesarias para proteger y estimular
una actividad productiva que nunca se desarrolló (ibíd., 95-96).

El análisis de Coatsworth implica que las instituciones formales coartaron la actividad empresarial y favorecieron la captura de rentas, 
en un contexto que se asemejaba más a una economía feudal que a una especie de protocapitalismo. La pesada carga fiscal impuesta a las actividades económicas las hacía costosas, y la poca claridad de los derechos de propiedad desalentó la iniciativa empresarial. Además, la fuerte división entre españoles y criollos limitó la formación de capital humano. En opinión de Semo (1973), la Corona estaba más interesada en mantener a los indígenas en condiciones de servidumbre, lo que los obligaba a pagar tributos en trabajo, especie y dinero.

Los ingresos de las clases dominantes [provenían] del trabajo excedente de los trabajadores indios de encomienda o repartimiento, los esclavos, los asalariados libres, los peones y la explotación comercial de la comunidad y el pequeño productor. [Tomaban] la forma de renta y ganancia (ibíd., 16).

No menos importante fue que la Corona instauró hábitos de ejercicio de la autoridad que llevaban a otorgar privilegios monopólicos por vínculos personales y desalentaban la libre empresa, y dieron origen a instituciones informales que hasta hoy influyen en forma perjudicial en el capitalismo mexicano:

La naturaleza intervencionista y continuamente arbitraria del medio institucional obligaba a cada empresa, fuese urbana o rural, a operar en forma sumamente politizada, aprovechando redes de parentesco, influencia política y prestigio familiar para ganar acceso privilegiado a créditos subsidiados, aplicar diversas estratagemas para reclutar mano de obra, cobrar deudas o aplicar contratos, evadir impuestos o la acción de los tribunales, o defender o afirmar derechos sobre la tierra. El éxito o el fracaso en el terreno económico dependían siempre de las relaciones del productor con las autoridades politicas (Coatsworth, 1990, 98; cursivas añadidas).

La organización económica heredad de la Colonia, conforme con la matriz institucional formal e informal mencionada, obstaculizó la formación y desarrollo del espíritu de empresa, y las formas de ejercer el poder y organizar la economía no se alteraron en el México independiente. Bértola y Ocampo (2013) también señalan que en América Latina se estableció una matriz institucional reacia al capitalismo que aún perdura.

\section{LA INDEPENDENCIA}

En la teoría, la lucha de independencia debía alterar la trayectoria histórica establecida en la Colonia para pasar de una sociedad de privilegios a una de derechos. Pero, como sugiere Coatsworth, la élite criolla conservó la matriz institucional y separó a México del proceso liberalizador que estaba en marcha en España, agrupando a la facción conservadora después de la Independencia. Por su parte, la facción liberal, formada por algunos generales, abogados, médicos, pequeños 
propietarios, comerciantes y filas medias del clero y del ejército, pugnaba por un cambio institucional que siguiera el ejemplo de Estados Unidos y Europa occidental (Coatsworth, 1990,103). La experiencia de medio siglo caracterizado por la inestabilidad en el gobierno demuestra que ninguno de esos grupos logró una hegemonía que diera estabilidad institucional a México.

Los grandes terratenientes e industriales del centro del país, sumados a la Iglesia católica, que buscaba preservar sus privilegios, "hicieron repetidos esfuerzos por recrear el centralismo arbitrario del Estado colonial" (ibíd., 100). De modo que los grupos que integraron la élite del poder, en vez de modernizar al país, mantuvieron una actitud conservadora de resistencia a la ruptura del orden colonial. Los primeros gobiernos eran débiles y dieron pie a caudillismos y caciquismos locales que se apropiaron del territorio, preservaron la estructura de tenencia y usufructo de la tierra y promovieron una organización "feudal o semifeudal” (ibíd., 101), que acentuaría la rigidez institucional y la improductividad. El breve régimen del emperador Maximiliano, apoyado por los conservadores, paradójicamente resultó liberal e intentó remover los obstáculos al desarrollo capitalista en vez de preservar la estructura feudal.

Maximiliano abrió el camino al liberalismo político de Benito Juárez, que al institucionalizarse mediante la ley perfiló el liberalismo económico y social. Pero ese liberalismo económico no se consolidó, entre otras cosas por las restricciones económicas del gobierno, que estaba en la ruina, y por la desarticulación de la estructura económica. De modo que el liberalismo mexicano solo se consolidó en el papel, pero no modificó el hábito arraigado de anteponer los intereses de las élites a la ley, y que aún perdura².

La ley no ha sido obstáculo para la vigencia de prácticas, negocios e intereses que están en franca contradicción con ella: corrupción, contratos ilegales, favores ilícitos, usurpación de funciones, etc. Este desfasamiento entre pacto y norma, en el que el primero estaría precediendo lógica y políticamente a la segunda, constituye uno de los principios estructurales en torno a los cuales se organiza la acción de los grupos dominantes y, dentro de ellos, del "empresariado" (Valdés, 1997, 80).

Como se sabe, durante el porfiriato hubo una mezcla de fuerte autoritarismo y modernización económica. Llevó a cabo una integración política vertical y alentó el crecimiento favoreciendo la inversión extranjera. Porfirio Díaz logró articular los intereses de las facciones

${ }^{2}$ Pese a su liberalismo, Benito Juárez no se alejó de los hábitos políticos tradicionales, como constata su célebre frase: "A mis amigos: justicia y gracia; a mis enemigos: justicia a secas”. Esa paradoja refleja la subordinación del Estado a los contubernios de la élite. 
liberal y conservadora mediante un poder dictatorial que estableció el orden en un país descarrilado y víctima del bandolerismo (Topik, 1990). Las concesiones férreas a compañías extranjeras mejoraron las comunicaciones e hicieron posible que los inversionistas extranjeros aportaran grandes volúmenes de capital a la industria y la minería, de modo que la dinámica económica favoreció más el capital foráneo que la formación de una burguesía empresarial nacional. Los "empresarios" nacionales no se asemejaban al empresario schumpeteriano, se formaron en el comercio y la banca (Valdés, 1997), en la lenta modernización de los hacendados tradicionales así como por la enajenación de los bienes eclesiásticos, en una economía dedicada predominantemente a actividades primarias. El ritmo de la industrialización dependía entonces de inversiones extranjeras concordantes con la segunda Revolución industrial, más que con la formación de una masa crítica de emprendedores nacionales.

Los rancheros del norte fueron actores decisivos en la Revolución pues fueron excluidos en los planes de industrialización de Porfirio Díaz. Los que no se sentían representados en la coalición gobernante y no se beneficiaban de la prosperidad económica (Valdés, 1997, 97) pugnaron, junto con los comerciantes, por redefinir su posición en la estratificación social. Al margen de la discusión sobre las causas de la Revolución, después de la aprobación de la Constitución de 1917, militares del norte como Carranza, Obregón y Calles se dedicaron a consolidar una estructura de poder personalista en pos del "desarro1lismo" económico, de tipo estatista:

E1 Estado debía crear las condiciones internas y externas para la acumulación
de capital [...] Esta idea, recogida como precepto en el artículo 27 constitu-
cional, abrigaría a la acción "revolucionaria" del gobierno y sentaría las bases
de un estilo de relación institucional con el sector privado que justificaría
mantenerlo legítimamente "marginado" (es decir, ilegitimado) del proceso de
decisiones y de la participación política activa. Este estilo no siempre fue in-
cómodo para el sector privado; sirvió para brindarle protección, pero también
para subordinarlo (Valdés, 1997, 103; cursivas del original).

E1 proyecto desarrollista de Obregón y Calles, asociado a la Revolución, reconocía que para lograr la legitimidad política y superar la inestabilidad política se requería una alianza con el empresariado, la cual según Valdés $(1997,104)$ buscaba: 1) el reacomodo de la élite económica del porfiriato a las nuevas condiciones; 2) la concesión de poder económico a la alta burocracia de la élite política, y 3) el surgimiento de una nueva capa de empresarios, la cual se fortaleció a partir de los años treinta. Estos tres propósitos hicieron posible la coalición entre los dueños del dinero y el grupo que resultó favorecido 
después de la Revolución, y que llegó a integrar la élite que controla la política, la economía y la sociedad en su propio beneficio, dejando poco espacio a la movilidad social (Rivera, 2009). La "familia revolucionaria" hizo acuerdos informales con industriales, banqueros y comerciantes, y así los cooptó.

Hamilton (1986) muestra cómo se asentaron los militares en el poder: se indujo a caudillos regionales para que lograran sus ambiciones personales creando empresas y no disputando el poder. La vieja oligarquía se acomodó al dominio político de los caudillos del norte para integrar sus intereses a los de la nueva élite (Valdés, 1997). Y el Estado naciente impulsó el capitalismo dirigido y la formación de la nueva clase capitalista (Hamilton, 1986, 127). Así se formó una burguesía dependiente de la gracia estatal basada en los intercambios personales que se había instaurado desde la Colonia. Ese capitalismo mexicano, de orientación "mixta", cobijó a la burguesía nacional y creó una estructura paralela de control corporativo dirigida por el Partido Nacional Revolucionario, primera versión del Partido Revolucionario Institucional (PRI). Desde entonces, el "nacionalismo revolucionario" dirigió la economía con un fuerte sesgo centralista.

Todo intento revolucionario proveniente de la cúpula que integró la nueva élite fue aprovechado por los grupos de militares y gradualmente de civiles que apuntalaron el uso patrimonialista del poder $y$ dejaron en segundo plano las proclamas revolucionarias de comienzos de siglo. La coalición en el poder aglutinó los intereses de la clase política y, en torno a ella, los del sector empresarial, mediante una retórica demagógica que se fue consumiendo en las arenas movedizas de la corrupción institucionalizada.

En suma, el sistema autoritario integró políticamente a los propietarios e impulsó el crecimiento económico, en una alianza que buscaba atenuar la incertidumbre garantizando los derechos de propiedad y alentando la inversión (Haber et al., 2002), los requisitos para la industrialización tardía (Hernández, 2013a, 68 y ss.).

\section{PERIODO POSREVOLUCIONARIO}

Dada la orientación desarrollista-nacionalista de los gobiernos posrevolucionarios fue necesario redefinir la relación con el capital extranjero, y el momento crucial fue el gobierno de Lázaro Cárdenas. Durante las tres primeras décadas del siglo xx el capitalismo mexicano se basó en la inversión extranjera y las exportaciones. Además de la Gran Depresión, la expropiación del petróleo generó tensiones que se 
agravaron con las medidas de política (fiscal, comercial y cambiaria) de apoyo a la burguesía nacional.

El tipo de organización industrial que se formó durante la industrialización por sustitución de importaciones (ISI) no favoreció la productividad ni la competitividad, puesto que este modelo llevó a subsidiar formal o informalmente las nuevas instalaciones industriales, sin importar el grado de innovación tecnológica u organizativa, y en vez de premiar la eficiencia, alentó la obtención de rentas (Jeannot, 2010). Existe entonces una continuidad entre la isi y el rentismo afincado desde finales del siglo xix (Campa, 2010, 364). Campa sostiene que en esa época se asumieron pocos riesgos, se mostró poca capacidad para innovar y una gran habilidad para obtener beneficios inmediatos. Actitudes empresariales correspondientes a lo que algunos autores llaman proteccionismo frívolo (Fajnzylber, 1988), el cual favoreció la obtención de "ganancias inmerecidas" (Pérez, 1992, 352) según los estándares de productividad y competitividad.

Paradójicamente, debido a la incapacidad para pasar de la industrialización sencilla a la compleja, en vez de alentar la sustitución de bienes industriales importados, se importaban bienes industriales producidos localmente. La política proteccionista dio lugar a élites empresariales (nacionales y extranjeras ${ }^{3}$ ) que tenían poder de negociación y recibían beneficios fiscales, comerciales y cambiarios. Ese entorno propició el oportunismo y fue aprovechado por quienes tenían "poder económico (financiero, comercial y más tarde industrial) para reclamar apoyos que llevaron a formar mercados altamente concentrados (grandes monopolios y oligopolios) en industrias como la tabacalera, la cervecera o la textil" (Campa, 2010, 381). Al fin de cuentas, la vida empresarial se enmarcó en una alianza subordinada pero con claros privilegios, producto de la integración política vertical que hizo posible un crecimiento relativo después de la Revolución, igual que antes de ella (Haber et al., 2002). El problema no es la formación de monopolios en sí misma, puesto que pueden innovas, sino el hecho de que los monopolios y oligopolios nacionales no se orientaron hacia actividades innovadoras, si bien tenían el capital suficiente para pasar de actividades simples a actividades complejas basadas en la innovación.

El periodo sustitutivo suele ser idealizado porque fue la base de lo que se ha llamado desarrollo estabilizador. Pero es claro que ante la necesidad de abrir espacios, cuando la presión de la crisis fiscal y

${ }^{3} \mathrm{La}$ industria automotriz es un ejemplo. Debido a los aranceles, las empresas extranjeras se asentaron en el país y, aprovechando vacíos legales, se consideraron empresas nuevas y se beneficiaron con derechos y privilegios de las empresas locales. 
crediticia puso límites al "desarrollismo" priísta, la élite económica y política cerró filas para acentuar sus privilegios y bloqueó la transición a una economía más moderna, concordante con el paradigma tecno-económico emergente en la década de 1970. La industrialización trunca de América Latina (Fajnzylber, 1988) obedece en gran medida a la reticencia de la élite económica para convertirse en un empresariado innovador, prefiriendo obtener ganancias inmediatas o de corto plazo en sectores tradicionales, como lo hace aún hoy, con la transnacionalización del capital doméstico (Hernández, 2013a).

\section{NEOLIBERALISMO}

Se suele decir que el neoliberalismo es la culminación, discursiva y real, del "nacionalismo revolucionario". Después de décadas de proteccionismo frívolo que llevaron al parasitismo, al desinterés tecnológico y a la dependencia de la renta petrolera, la modernización de la economía era prometedora en el discurso. Cuando se enfrentó la crisis de los ochenta, augurada desde finales de los setenta, la ruptura con el modelo ISI, basado en la hegemonía del PRI y el control corporativo de la clase trabajadora, fue una oportunidad para reorientar el capitalismo mexicano.

Pero pese a que la retórica de la tecnocracia económica que encabezó las reformas prometía la modernización, no modernizó la estructura institucional y, lejos de alterar la red de componendas y privilegios entre las élites económica y política, solo redefinió a sus actores (Hernández, 2013a). Impulsó reformas que, en vista de los resultados, solo intercambiaron a los beneficiarios de las rentas monopólicas. En vez de que las sobreganancias fueran a manos del gobierno, se privatizaron sin transparencia, mediante acuerdos informales (Valdés, 1997, 237), lo que concentró aún más la riqueza en manos de unos pocos grupos empresariales. E1 parteaguas fue el sexenio de Carlos Salinas, quien redefinió el marco institucional formal de la economía y trazó el camino para convertir al Estado propietario e interventor en gestor de los grandes capitales, a los que se atribuyó el papel de actores primordiales de la modernización (Hernández, 2013a, 104-107).

E1 mercado nacional sigue estando concentrado en grandes grupos monopólicos y oligopólicos, lo que indica que no se ha alterado la alianza estructural entre las élites política y económica, y aunque nuevos grupos ingresaron a la élite, el comportamiento empresarial mantiene su orientación a la búsqueda de rentas. Entre las personas 
más ricas de América Latina en 2016, tres son mexicanas: Carlos Slim, Germán Larrea y Alberto Baillères (ver cuadro 1).

Esas tres personas encabezan conglomerados comerciales y financieros que controlan las actividades en los campos de los servicios, la minería y la construcción. Slim posee el Grupo Carso (que controla el comercio, la fabricación de autopartes y la construcción), Inbursa (grupo financiero), Telmex (telefonía) y América Móvil (telecomunicaciones), que aumentó su fortuna con la privatización de Telmex, antigua empresa del Estado que se vendió a Slim en el sexenio de Carlos Salinas de Gortari; después de esta adquisición ha extendido sus inversiones a casi toda América Latina (Hernández, 2013). Larrea encabeza el Grupo México, el grupo minero más poderoso del país y uno de los principales productores de cobre en el mundo, y es el mayor accionista de Empresarios Industriales de México y de la Compañía Perforadora de México. Alberto Baillères está a la cabeza de Grupo Bal, integrado por el Grupo Nacional Provincial (seguros), el Grupo Palacio de Hierro (tiendas de departamentos), el Grupo Peñoles (minería y metalurgia), el Grupo Profuturo (fondos de pensiones), Valmex (Bolsa) y el Instituto Tecnológico Autónomo de México (IтAм), el principal centro educativo de la élite que manejan la política económica. Las grandes fortunas de estos grandes potentados aún provienen de actividades tradicionales, como las de los grandes magnates de siglos pasados, de carácter extractivo y financiero-rentista. Falta recorrer un largo camino para que en México se dé cabida a empresarios cuya fortuna provenga de la innovación y el conocimiento.

Cuadro 1

Las diez personas más ricas de América Latina

(Millones de dólares)

\begin{tabular}{lllr}
\hline 1. Carlos Slim & 50.000 & 6. Iris Fontbona & 10.100 \\
2. Jorge Paulo Lemann & 27.800 & 7. Germán Larrea Mota & 9.200 \\
3. Joseph Safra & 17.200 & 8. Luis Carlos Sarmiento & 8.900 \\
4. Marcel Hermann Telles & 12.900 & 9. Alberto Baillères González & 6.900 \\
5. Carlos Alberto Sicupira & 11.300 & 10. Eduardo Saverin & 6.200 \\
\hline
\end{tabular}

Fuente: www.forbes.com.mx/los-mas-ricos-en-latinoamerica-en-2016/

Durante el periodo neoliberal, el manejo de la política económica se entregó prácticamente a egresados de un centro de enseñanza que propaga la ortodoxia, el ITAM, encabezado desde 1983 por dichos egresados. El IтAM es

el semillero de los gestores y cuadros administrativos, teóricos y contables del mundo empresarial mexicano; un formador de tecnócratas [...] es, en la 
práctica, el plantel de donde han egresado economistas y administradores que han controlado la conducción de la política económica del país desde la década de los ochenta. Su influencia en el poder político va en ascenso (Petrich, 2007, 129).

En el iтAM se formaron dos de los tres gobernadores del banco central, el Banco de México y siete de los once secretarios de Hacienda, responsables de la política fiscal (cuadros 2 y 3 ).

Cuadro 2

Gobernadores del Banco de México, desde 1983

\begin{tabular}{lll}
\hline Nombre & Estudios en México & Estudios en el exterior \\
\hline Miguel Mancera Aguayo & $\begin{array}{l}\text { Licenciatura en Economía, } \\
\text { ITAM }\end{array}$ & $\begin{array}{l}\text { Maestría en Economía, U. } \\
\text { de Yale }\end{array}$ \\
Guillermo Ortiz Martínez & $\begin{array}{l}\text { Licenciatura en Economía, } \\
\text { UNAM } \\
\text { Licenciatura en Economía, } \\
\text { Agustín Carstens Carstens en Economía, U. } \\
\text { ITAM }\end{array}$ & $\begin{array}{l}\text { Doctoradord } \\
\text { de Chicago Economía, U. }\end{array}$ \\
\hline
\end{tabular}

Fuente: adaptado de Hernández (2011).

Cuadro 3

Secretarios de Hacienda y Crédito Público, desde 1983

\begin{tabular}{|c|c|c|}
\hline Nombre & Formación en México & Estudios en el exterior \\
\hline Jesús Silva Herzog Flores & $\begin{array}{l}\text { Licenciatura en Economía, } \\
\text { UNAM }\end{array}$ & $\begin{array}{l}\text { Maestría en Economía, U. } \\
\text { de Yale }\end{array}$ \\
\hline Gustavo Petricioli Iturbe & $\begin{array}{l}\text { Licenciatura en Economía, } \\
\text { ITAM }\end{array}$ & $\begin{array}{l}\text { Maestría en Economía, U. } \\
\text { de Yale }\end{array}$ \\
\hline Pedro Aspe Armella & $\begin{array}{l}\text { Licenciatura en Economía, } \\
\text { ITAM }\end{array}$ & Doctorado en Economía, MIT \\
\hline Jaime Serra Puche & $\begin{array}{l}\text { Licenciatura en Ciencias } \\
\text { Políticas, UNAM. } \\
\text { Maestría en Economía, } \\
\text { Colmex }\end{array}$ & $\begin{array}{l}\text { Doctorado en Economía, U. } \\
\text { de Yale }\end{array}$ \\
\hline Guillermo Ortiz Martínez & $\begin{array}{l}\text { Licenciatura en Economía, } \\
\text { UNAM }\end{array}$ & $\begin{array}{l}\text { Doctorado en Economía, U. } \\
\text { de Stanford }\end{array}$ \\
\hline José Ángel Gurría Treviño & $\begin{array}{l}\text { Licenciatura en Economía, } \\
\text { UNAM }\end{array}$ & $\begin{array}{l}\text { Maestría en Finanzas } \\
\text { Públicas, U. de Leeds }\end{array}$ \\
\hline Francisco Gil Díaz & $\begin{array}{l}\text { Licenciatura en Economía, } \\
\text { ITAM }\end{array}$ & $\begin{array}{l}\text { Doctorado en Economía, U. } \\
\text { de Chicago }\end{array}$ \\
\hline Agustín Carstens Carstens & $\begin{array}{l}\text { Licenciatura en Economía, } \\
\text { ITAM }\end{array}$ & $\begin{array}{l}\text { Doctorado en Economía, U. } \\
\text { de Chicago }\end{array}$ \\
\hline Ernesto Cordero Arroyo & $\begin{array}{l}\text { Licenciatura en Actuaría, } \\
\text { ITAM. Maestría en Economía, } \\
\text { ITAM }\end{array}$ & $\begin{array}{l}\text { Maestría en Economía, U. de } \\
\text { Pennsylvania }\end{array}$ \\
\hline $\begin{array}{l}\text { José Antonio Meade } \\
\text { Kuribreña }\end{array}$ & $\begin{array}{l}\text { Licenciatura en Economía, } \\
\text { ITAM }\end{array}$ & $\begin{array}{l}\text { Doctorado en Economía, U. } \\
\text { de Yale }\end{array}$ \\
\hline Luis Videgaray Caso & $\begin{array}{l}\text { Licenciatura en Economía, } \\
\text { ITAM }\end{array}$ & Doctorado en Economía, MIT \\
\hline
\end{tabular}

Fuente: adaptado de Hernández (2011).

E1 hecho de que la élite que dirige la política económica tenga un origen común no es extraño, y tampoco que haya hecho estudios de posgrado en el extranjero. Lo que es llamativo es el mal desempeño 
de la economía mexicana, la agudización de los problemas sociales y el aumento de las desigualdades durante el periodo en que los egresados del IтAM, fundado por Raúl Baillères, padre de Alberto Baillères González, han ejercido la hegemonía en el diseño y la ejecución de la política económica del país, promoviendo el rentismo en vez del desarrollo económico basado en el conocimiento científico y la innovación tecnológica.

\section{CONCLUSIONES}

Los países que hoy son pobres también lo eran en el pasado, en los siglos XVIII y XIX, cuando se difundió y consolidó el capitalismo. En ese largo periodo el crecimiento económico de América Latina fue mínimo, con largos lapsos de estancamiento y años de retroceso. A ello contribuyeron siglos de colonización, un freno impuesto por el poderío de la metrópoli, que lejos de afianzar hábitos productivos en la población, concentró la extracción de riqueza en pocas manos. La historia económica de México como nación independiente no se puede entender al margen de las condiciones institucionales que han permitido que las élites que determinan su dirección histórica la hayan trazado desde una perspectiva patrimonialista. El rentismo, afín a esa forma oligárquica de ejercicio del poder, ha sido una persistente traba institucional que se refleja en la reticencia hacia comportamientos innovadores.

Después de la Independencia, que podría haber alterado la senda de atraso, corrupción e injusticia social, las élites novohispanas fueron sustituidas por grupos interesados en mantener sus privilegios más que en sentar las bases de un país incluyente y productivo. Por ello, durante la mayor parte del siglo XIX el país padeció una gran inestabilidad institucional; la construcción de vías de comunicación y la modernización de la actividad productiva para emplear mejor los recursos se postergó hasta las postrimerías del siglo XIX, impulsadas por el capital extranjero favorecido por el porfiriato, sin que se modernizaran los potentados locales. El capitalismo mexicano se desarrolló en forma dependiente, primero subordinado a países europeos y luego a Estados Unidos, sin un proyecto nacional consistente.

Luego de la Revolución se procedió a una integración política vertical y se formó una nueva oligarquía política que usó la inversión pública como motor de crecimiento favoreciendo a grupos de capitalistas nacionales que, con un mercado protegido de la competencia externa y sin competencia interna, no tenían que asumir riesgos e introducir innovaciones. Y se formaron monopolios y oligopolios, 
públicos y privados, que aún generan sobreganancias y rentas de monopolio que no se invierten en las ramas emergentes del nuevo paradigma tecno-económico impulsado desde finales de los años setenta del siglo pasado.

Esos rasgos de comportamiento persistieron en el periodo desarrollista, que solo logró un crecimiento económico visible pero no el desarrollo. E1 “desarrollo estabilizador" sentó bases para alterar la trayectoria histórica e institucional, pero no se consolidó por la renuencia del régimen prísta a abandonar el autoritarismo y la complicidad con los grandes capitalistas locales, con los que mantenía alianzas corporativas. La crisis de la estrategia del "nacionalismo revolucionario" impuso el neoliberalismo y fue una oportunidad para romper los acuerdos de la cúpula, pero el gobierno de Salinas, que trazó un nuevo diseño institucional, solo modificó la participación de las élites, con una opacidad institucional que a la larga provocó la pérdida de sectores clave, como la banca y las cadenas comerciales que quedaron en manos de empresas extranjeras.

A la luz de este breve repaso, y considerando que la industrialización requiere grandes cambios institucionales y una estrategia coherente de modernización económica, es necesario cuestionar las decisiones que afectan a todo el país. Mucho se ha insistido en la necesidad de que el Estado retome la función de orientar la política económica hacia actividades productivas capaces de competir en el plano internacional, aunque la evaluación de las experiencias de los países tardíos А у в exige superar la abstracción de una estrategia desarrollista, pues la intervención de cada Estado debe tener modalidades específicas y adecuadas para que sea eficaz.

$\mathrm{El}$ análisis institucionalista ayuda a identificar el patrón de comportamiento de las élites y las estructuras que se auto perpetúan en una trayectoria histórico-institucional que actúa como "camisa de fuerza" y bloquea la actividad innovadora. Después de la Independencia las élites mexicanas mantuvieron la orientación extractiva, la desigualdad y la corrupción que se instauraron durante la Conquista, y continuaron la sucesión de grupos oligárquicos. El poder económico y el poder político están imbricados desde entonces, de modo que el desempeño económico se basa en la interrelación entre grandes negociantes y poder político más que en la eficacia y en los estándares del mercado; lo que sugiere que las instituciones informales perduran más que las formales y las moldean, creando trabas institucionales.

Puesto que la élite empresarial se ha dedicado a la caza de rentas, aún no existe una masa crítica de empresarios dispuestos a asumir 
riesgos, a ser creativos e invertir en nuevos procesos que desaten la innovación en forma regular. Lo que predomina es un tipo de rentistas que concentra el poder económico mediante rentas de monopolio, en actividades extractivas y financieras, por sus conexiones con el poder político.

\section{REFERENCIAS BIBLIOGRÁFICAS}

1. Acemoglu, D.; S. Johnson y J. A. Robinson. "The colonial origins of comparative development", American Economic Review 91, 5, 2001, 1369-1401.

2. Arellano G., D. y W. Lepore. "Poder, patrón de dependencia y nuevo institucionalismo económico", Gestión y Política Pública 18, 2, 2009, pp. 253-305.

3. Bértola, L. y J. A. Ocampo. El desarrollo económico de América Latina desde la independencia, México DF, Fondo de Cultura Económica, 2013.

4. Campa, J. I. "La formación de una clase empresarial rentista", F. Jeannot, coord., Las instituciones del capitalismo occidental, México DF, UAM-Sísifo, 2010.

5. Coatsworth, J. H. Los orígenes del atraso, México DF, Alianza, 1990.

6. Dabat, A.; M. Á. Rivera y S. Sztulwark. "Rentas económicas en el marco de la globalización: desarrollo y aprendizaje", Problemas del Desarrollo 38, 151, 2007, pp. 11-36.

7. Fajnzylber, F. La industrialización trunca de América Latina, México DF, Nueva Imagen, 1988.

8. Galbraith, J. K. El nuevo Estado industrial, Madrid, Sarpe, 1984.

9. Haber, S.; N. Maurer y A. Razo. "Sustaining economic performance under political instability: Political integration in revolutionary Mexico", S. Haber, ed., Crony capitalism and economic growth in Latin America: Theory and evidence, Stanford, Stanford University Press, 2002.

10. Hamilton, N. "E1 Estado y la formación de la clase capitalista en el México posrevolucionario", J. Labastida, comp., Grupos económicos y organizaciones empresariales en México, México DF, Alianza, 1986.

11. Hernández L., M. H. "La inercia ideológica del neoliberalismo: las raíces de la mediocridad económica en México", Redpol 3, 2011, pp. $1-27$.

12. Hernández L., M. H. "Matriz institucional y gobernanza corporativa", Gestión y Estrategia 42, 2012, pp. 17-34.

13. Hernández L., M. H. La transnacionalización del gran capital en México, México DF, unam-FCA, 2013a.

14. Hernández L., M. H. "Modernización y crisis en México", en M. H. Hernández L., coord., Entorno de las organizaciones, México DF, UNAM-FCA, 2013b.

15. Hoff, K. y J. E. Stiglitz. "La teoría económica moderna y el desarrollo", G. M. Meier y J. E. Stiglitz, eds., Fronteras de la economía del desarrollo, Bogotá, Banco Mundial-Alfaomega, 2002.

16. Jeannot, F. "La dependencia de la trayectoria en América Latina", F. Jeannot, coord., Las instituciones del capitalismo occidental, México DF, UAM-Sísifo, 2010. 
17. Jeannot, F. "Fluctuaciones cíclicas en Schumpeter", Análisis Económico 17, 35, 2002, pp. 43-77.

18. Lederman, D. et al. El emprendimiento en América Latina. Washington Dc, Banco Mundial, 2014.

19. Leff, N. H. "E1 espíritu de empresa y la organización industrial en los países menos desarrollados: 'los grupos”, El Trimestre Económico 61, 3, 1974, pp. 521-541.

20. Mills, W. C. La élite del poder, México DE, Fondo de Cultura Económica, 1957.

21. North, D. C. Understanding the process of economic change, Princeton, NJ, Princeton University Press, 2005.

22. North, D. C. Instituciones, cambio institucional y desempeño económico, México DF, Fondo de Cultura Económica, 1993.

23. North, D. et al. Violence and social orders, Nueva York, Cambridge University Press, 2009.

24. Peña, E. de la. "Instituciones endógenas y herencia colonial en el capitalismo latinoamericano", F. Jeannot, coord., Las instituciones del capitalismo occidental, México DF, UAM-Sísifo, 2010.

25. Pérez, C. "La modernización industrial en América Latina y la herencia de la sustitución de importaciones", Comercio Exterior 46, 5, 1996, pp. 347-363.

26. Petrich M, B. "Alberto Baillères, simplemente Palacio", J. Zepeda P., coord., Los amos de México, México DF, Planeta, 2007.

27. Rivera R., M. Á. Desarrollo económico y cambio institucional, México DF, UnAM-Juan Pablos, 2009.

28. Rivera R., M. Á. Trayectorias históricas de desarrollo, México DF, UnAM, 2014.

29. Salas-P., A. 2006. "Fuerzas centrípetas y centrífugas en la red corporativa mexicana (1981-2001)”, Revista Mexicana de Sociología 68, 2, 2006, pp. 331-375.

30. Schumpeter, J. A. Capitalismo, socialismo y democracia, Barcelona, Orbis, 1983.

31. Schumpeter, J. A. Teoría del desenvolvimiento económico, México DF, Fondo de Cultura Económica, 1997.

32. Semo, E. Historia del capitalismo en México: los orígenes, 1521-1763, México DF, Era, 1973.

33. Serfati, C. "La lógica financiero-rentista de las sociedades transnacionales", Mundo Siglo XXI 8, 29, 2013, pp. 5-21.

34. Topik, S. "La Revolución, el Estado y el desarrollo económico en México", Historia Mexicana 40, 1, 1990, pp. 79-144.

35. Valdés U., F. Autonomía y legitimidad, México DF, Siglo xxi, 1997.

36. Veblen, T. Teoría de la clase ociosa, México DF, Fondo de Cultura Económica, 1974. 